\title{
The Shared Economy in the Current Market
}

\author{
Tatiana Sorokova ${ }^{1}$, Daniela Petrikova $^{2}$ * \\ ${ }^{1}$ Technical University of Kosice, Faculty of Economics, Department of Economic Theories, \\ Nemcovej 32, 04000 Kosice, Slovakia \\ ${ }^{2}$ Technical University of Kosice, Department of Engineering Education, Nemcovej 32, 04000 \\ Kosice, Slovakia
}

\begin{abstract}
This paper presents the characteristics of the shared economy phenomenon. The theoretical part focuses on the activities of the shared economy in the current international market environment. We describe the categorization of shared economy activities across platforms. We devote ourselves to measuring a shared economy because it also generates many values that are not fully captured in GDP data. The global value of the shared economy is only an estimate. We also deal with threats to the shared economy as these can also be seen as a growing network of unregulated digital markets. These pose a threat to regulated businesses and to consumers. Shared economic platforms are different in national economies. They are highly criticized in some economies because they create unfair competition conditions. They create illegal, black or gray markets or support, for example, tax avoidance. The shared economy also generates many values that are not fully captured in GDP figures. The research part of the paper consists of an UBER analysis in selected countries. At present, UBER is one of the most widespread structures of the shared economy compared to classic taxis. The analysis offers a comparison of the UBER platform, which can bring a new perspective on shared economy issues. The selected indicators are country-specific and collected for two periods: before the UBER come to country and after that.
\end{abstract}

\section{Introduction}

The concept of shared economy functions based on a principle of exchanging goods and services at the level of customers, businesses, governments and other subjects within economies. Conventional way of an exchange which has been in place until now was based on basic exchanges via money transfers; however, this traditional way is not necessary anymore for exchanging goods and services.

\section{Shared Economy}

Porter and Kramer [1] stated that shared economy is derived from increased amount of competition in market environment. In this environment, business subjects execute

\footnotetext{
*Corresponding author: daniela.petrikova@tuke.sk
} 
preference of choice towards so-called self-serviced exchanges. The self-serviced exchange is becoming an alternative for achieving the utilization of individuals and at the same time it includes social values typical for communities. According to both authors, these attributes are naturally derived from relatively dynamic development of globalization over last few decades. The sharing economy has been changing the way that people share and conduct transactions in digital spaces. This phenomenon has drawn scholars from a large number of disparate fields and disciplines into an emerging research area. [2] According to Owyang [3] there are over 200 companies focused on doing business in the sphere of shared economy. This number is not truly relevant, due to continuous development of business subjects and continuous development of new types and possibilities of shared economy platforms. Additionally, we can conclude that for all shared economy platforms there is a common denominator which is online technologies. Growth of shared economy was based on interconnectivity via internet which enables to reduce transaction costs of business subjects and increase scale of their activities. [4] New technological possibilities such as cloud, sharing information about traffic situations, inputting information into maps, social media have enabled exchanges of goods and services. These technologies also showed how owners of assets are now capable to place their goods and services into marketplace on larger scale without considerable expansion of their capacities. The development of internet usage over last decade enabled utilization of vast amount of consumer data which paved the way for broader and smoother search for subjects with goods and those who have desire or need for those goods. This concept of dynamic market can be described in different academic publications by other than "shared economy" terms, such as economy based on cooperation, cooperative economy, peer-to-peer economy or others. Sharing economy platforms combine organizational and market mechanisms in innovative ways to gain competitive advantages over incumbents. These mechanisms are combined on two key dimensions: tight or loose control over participants, and high or low rivalry between participants. [5] The rapid development of the sharing economy has brought positive effects to many people, but it has also led to some negative consequences. [6]

\section{Measuring the shared economy}

Shared economy covers everything from home appliances to land use. Development of scale of shared platforms has created a new problem associated with measuring the shared economy. Calculation of gross domestic product (GDP) of any country should include costs associated during exchanges amongst subjects involved in shared economy, which are currently not being recorded in the gross domestic product. ccording to the World Economy Forum [7], there are four aspects identified in shared economy utilization, which are not included in calculation of GDP.

1. Unaccounted economic profits: There is an economic activity which is contributing to productions; however, this activity is not included in calculations of GDP. [7]. For instance, an excellent example is platform which offers advisory or references in sphere of leisure accommodation which is being utilized by consumers and therefore there is no need to use the services of travel agencies. Another example is a utilization of social network, where registered users participate in exchanges of clothes or house goods used in households. These kinds of exchanges provide participating consumers with higher benefits and added value; although, these benefits are not being transferred into calculations of GDP. Another associated outcome is certain management of financial resources leading towards savings and those savings are in many cases redirected by economic subjects towards another parts of economy (e.g. purchases of different/another goods) - which can eventually increase overall GDP. The issue here is that in real life individual consumers can generate economic benefit which doesn't have to be reflected in GDP. [7-9] 
2. Improved usage of environmental resources: According to World Economic Forum [7], personal vehicles are on average parked $95 \%$ of time which means that those vehicles are mostly used for transportation to work and back home. This shows that there is a unique opportunity to share automobiles which creates positive externalities which do not generate additional production and therefore the usage of natural resources is capped which is associated with positive effects on environment and lowered waste production. [7-9] The GDP does not sufficiently consider this impact of mentioned attributes such as reduction in consumption of natural resources used for construction and its impact on environment.

3. Increase of personal ease: Gross domestic product is not designed to measure social progress which is important indicators of wellbeing, because this indicator exceeds the scale of simple economic injunctions which includes factors such as quality of life including social and psychological health. Social aspects of shared economy are not included in calculations of GDP despite the fact that those aspects are significantly contributing to satisfaction with life. [7,9] Additionally, consumers and service provides tend to achieve certain social benefit due to time spend together and based on interactions which is not measured by monetary expressions. Based on all of the stated findings, there is an increase in individual wellbeing and individuals' added value which does not tend to be express by traditional economic indicators.

4. Higher worth of social possibilities and consumer surpluses: two interconnected concepts of values in economy which are connected to shared economy via utilization of resources; although, those concepts are not measured by GDP. Higher worth of social possibilities is the value of willingness of people to pay for maintenance of public property or public service, even if there is a little or zero chance that they are going to use this property or service. People are willing to pay for goods or services just to have an option to use it in specific time which is suitable for them even if they agree with this need or not. Specific examples which fit both statements are public parks and public transportation. Costs associated with those properties, goods and services are significant; however, neither of those benefiting prospects is included in calculations of GDP but all of those examples are part of shared economy benefits. $[8,10]$ Consumer surplus is a difference between price the consumer is willing to pay and the price which consumer is actually paying. The consumer surpluses are generated by excessive supply or utilization of excessive capacities. For instance, in order to achieve lower taxi prices there is no need to increase amount of taxis in particular location, but there is a possibility to increase the amount of passengers for each ride which will increase the overall amount of passengers driven for lower prices per passenger with the same amount of taxis. According to study of The United States Council for Automotive Research, the estimate is that one "car pool" can supplement number of cars which would be in other case driven. [10] The lower level of waste expands the supply which decreases the prices and this leads to increased value of consumer surpluses. Neither of those factors stated so far are included in calculations of GDP. [8] According to Coyle [11] the impact of shared economy resources on current statistics could be even negative. For instance, the desire to use motor vehicles amongst more users could lead to lesser desire to buy own motor vehicle. Reduction of consumptions does not have to lead to reduction of wealth. The increase of effectivity and time saving which is derived from usage of digital applications and similar platforms of shared economy are as well not included in calculations of GDP. [12] In case of national accounts, it is still necessary to answer large number of questions linked to statistical challenges with a goal to measure and identify the shared economy sources as a whole. The main challenges are classification of these activities in current and future statistical classifications, and specifically the need to identify transactions realized between consumers and households and need to measure nonmonetary transactions. The fact that activities in shared economy are currently not included in any official statistical indicators is clearly stated by Bean. [13] According to Charles 
Bean study, current methods of calculation of those statistics are based on traditional assumptions that businesses are creating added value as producers, when in the meanwhile, individuals and households are only consumers (or investors). Currently, there is an increase in amount of individuals who are directly involved in activities connected to shared economy. Due to continual increase of supply of goods and services offered by households in shared economy there is certain skewness of real marginal values generated by businesses. Added values created by individuals and households are currently included in national accounts via estimates for informal economy. [13] The problems of evaluation of effects of shared economy are being researched by number of institutions. Eurostat created a working group in 2017 to focus on measuring the prices and volume of activities in sphere of services. The working group stated that there is a risk of distortion due to introduction of new digital services and it recommended that every case will be assessed separately. The Committee on Statistics and Statistical Policy of OECD established in 2016 an informal discussion group about measuring the GDP in digital economy with the goal of solving the problems in connection to measuring the digital economy. The meeting of the United Nations Economic Commission for Europe about national accounts which was held in May 2018 was focused on presenting the proposal for creation of satellite account for digital economy within national accounts. This would allow clear identification of digital transactions in case of need to correctly classify the large transaction. These discussions about proposed satellite account are still in very early stages. [14] Owyang [3] presented the work which has been for some years analyzing development of shared economy and this work is paying the special interest towards differentiated companies based on their activities. Furthermore, the presented work shows that this categorization can offer more detailed specification and information about real fields of activities on various platforms. Based on this, the goal is to create a road for understanding of functionality of platforms and at the same time to connect those platforms with traditional forms of economies. Owyang presents individual categories in following categorizations: Personal services; General online rental; Taxi sharing; Miscellaneous services; Peer-to-peer rental; Crowdfunding; Car sharing; Neighbourhood rental/share/market; Gardens; Car Sharing (from auto Companies); Unique Experiences; Skill Sharing; Peer-to-Peer Car Sharing; Peer-to-Peer Travel; Big Marketplaces; Bike sharing; Errand/task networks (general and professional); Free/gift exchanges; Ride sharing; Social food networks; Used electronics; Solar power; Storage networks; Swap sites for books/media; Toy rental; Parking spots; Swap sites baby goods/toys; Textbook rental; Shared studios/workshops/workspaces; Clothing swaps; Art rental; Social lending; Pets; Fashion rental; Social currencies; Education/language; Movies. This classification is fairly simple and at the first glance it shows what organizations are operating in specific industries. This simplicity does not leave a room for information system which allows consumers to realize business activities. The shared economy includes new types of business models which have potential to disturb current sectors or industries. Based on the fact that shared economy is mostly derived from vast usage of technologies and is being constantly developed, it is important to realize that new and developing business models are crucial for activities of associated platforms. [15]

\section{Uber - example of shared economy}

Watanabe, Naveed, Neittaanmäki and Fox [16] examined the institutional sources contrasting success and failure in Uber's global expansion. Their comparative empirical analysis was identified that the contrast could be attributed to a bipolarization nature of ICT-driven logistic growth, and the success can be attributed to a coevolutionary acclimatization that harnesses the vigor of counterparts. 
Thelen [17] uses the case of the transportation network company Uber as a lens to explore the comparative politics of the platform economy in Europe and the United States. Different countries have responded in very different ways to this new service, from welcome embrace and accommodating regulatory adjustments to complete rejection and legal bans. The popular Uber Sharing Service has influenced the taxi industry by providing lower prices, faster and better service, as well as a higher level of transparency regarding driver selection and fare. Pepic [18] examines Uber. She investigates whether Uber represents loyal or false price competition to taxis by significantly lowering prices, lowering fixed costs and circumventing intermediaries. The taxi industry is highly regulated and has limited access. Driving sharing services such as Uber, which uses mobile internet technology to connect passengers and drivers, have come to compete with traditional taxis. Cramer and Krueger explore the efficiency of taxi-sharing services. [19]

Activities of company UBER are classified according to NACE 52.29 as "Other transportation support activities". For further clarification, the following classification of services sector shows what activities are covered by UBER platform: H Transportation and Storage; 49 Land transport and transport via pipelines; 49.3 Other passenger land transport; 49.31 Urban and suburban passenger land transport; 49.32 Taxi operations; 49.39 Other passenger land transport n. e. c.; 52 Warehousing and support activities for transportation; 52.2 Support activities for transportation; 52.29 Other transportation support activities (Uber).

Company UBER is focused on expanding its activities to countries all over the world. Despite its increasing popularity, the UBER is still facing large number of problems in most of the countries which is trying to enter and to start operate. There are presented examples from some countries with actual dates of entry into the markets and specific problems which UBER had to face at the specific times. Deeper analysis of UBER activities over last decade in countries where it operated could provide some characteristics of evidence about how this company could cooperate with some countries in future.

Currently, there are no publicly available relevant data about activities of UBER in individual countries and the impact of those activities in particular countries. The UBER has on its websites information about what country it has entered and when this entry was achieved. In some of those countries, the activities of UBER were banned or capped. We have selected some countries in Europe, for which we monitored the changes in economic indicators based on operation of UBER in observed countries (comparison of two time periods: before and after entry of UBER into the market). There are number of differences amongst selected countries, such as size of economy, development stage of economy, relationship towards services and transport. Due to the unsatisfactory available complex data about operations of taxi companies in individual countries during period of last decade, we have analyzed indicators from classification of NACE which are the closest to targeted analytical observations such as classification 49.32 Taxi services. The analytical data coverage included transport, storage and roads (in bn. USD), ground personal transport (per person in mil. $\mathrm{km}$ ), scale of personal transport to GDP and industry turnover of ground transport and transport via pipeline.

Gathered data of indicators for each individual country were tested via Shapiro-Wilk test which focuses on testing of normality of frequentist statistics at the alpha level of significance of $p=0.05$. If the data were sourced from normal distribution, those data would need to be submitted to dual selection of paired t-test for median and if some data weren't from normal distribution then those data would be tested via dual selection of Wilcoxon test. This test would test, whether there was a chance of average values during both time periods in individual country and whether this change was significant. In case of significant differentiation of average values, we would try to determine what kind of factors would cause this. This search for particular reason was required from the perspective of low 
representation of taxi services - which is at level of only $4 \%$ of the overall indicator - in classification group of NACE H Transportation, storage and roads.

\section{Uber in Czech Republic}

Date of entry: August 2014. Problems and challenges: - Opposition from taxi companies; Call to open branch in country, -Upcoming liberalization of legislation for taxi companies. Based on analysis of indicators from Transport, storage and roads, it shows that after market entry of UBER into Czech Republic in 2014, there were not statically significant changes between 2015 and 2017, in comparison to 2012-2014. However, the indicator Ground personal transportation shows from 2015 that there was a difference in increased average values which is statistically significant. Besides that, since 2014, it was confirmed that there was a significant change in testing of other indicators, such as net national income, added valued of services as percentage of GDP and Industry turnover of ground transport and transport via pipeline which includes the sphere of taxi services. The UBER had its operations limited to only capital city which means that those indicators were not influenced by the entry of UBER.

\section{Uber in France}

Date of entry: December 2011. Problems and challenges: - Accusation of monopolization of the market; - Tightening of legislature. The indicator Transport, storage and roads during years 2008-2011 and during years 2012-2017, shows based on testing under double selection of t-tests that in second term there was an increase in average values of indicators which is statistically significant. Besides this, the change in indicator Industry turnover of ground transport and transport via pipeline also showed as statistically significant which resulted in increased average value since 2011. After testing of other indicators such as Scale of personal transport to GDP and Ground personal transport there were not found statistically significant differences between tested periods. The data limitations in this case disallowed us from further verification whether there is monopolistic position on the market of taxi services that could have significant influence on changes of indicator. It is important to consider that railway transport in this country is still very popular amongst general public.

\section{Uber in Lithuania}

Date of entry: November 2015. Problems and challenges: - Opening the branch of UBER; Investment of UBER into technologies; - Partnership with government of country; Upholding the legislation for taxi companies. Data behind indicator Transport, storage and roads had increased after market entry of UBER in Lithuania during years 2016-2017 in comparison to years 2014-2015. However, this change was not statistically significant. Similarly, the same results were achieved under indicators of Industry turnover of ground transport and transport via pipeline. It is important to consider that Lithuania created same environment for UBER as for taxi services right upon the market entry of UBER in November 2015. Favorable business environment, fast adaptation and probably as well lifelike trust of population had benefited UBER in this country and within the market. Currently, the market of taxi services is rapidly changing and new competitors are coming to the market. 


\section{Uber in Poland}

Date of entry: August 2014. Problems and challenges: - Opposition from taxi companies; Competition from local platform Taxify; - Call to obtain license for drivers; - Upcoming tightening of legislation; - UBER opens the centrum for research and development and is offering employment. Dual selection pair t-test compared data from indicator Transport, storage and roads during years 2012-2014 before market entry of UBER and after its entry during years 2015-2017. It was shown that average value in second period was bigger and it was as well statistically significant. At this time UBER was not legalized in the country; however, its fast expansion into number of city could possibly influence the tested indicator. Other factors which could influence the indicator were development of infrastructure, such as railroad, which was one of the significantly developing types of transportation in Poland. In this case, the statistic about Scale of personal transport to GDP is more interesting. This indicator shows that over last few years this metric has been decreasing significantly and therefore its average value during period after market entry is lower than before the market entry. This change was measured as statistically significant.

\section{Uber in Great Britain}

Date of entry: July 2016. Problems and challenges: - Accusation of discrimination of workforce; - Call to offer paid holidays and minimal wages for its drivers; - Offering insurance coverage; - Court trials lasting 3 years; - Opposition from taxi companies; Upcoming tightening of rules; - Ban of UberPOOL. The analysis of differences between market entry of UBER during years 2014-2015 and after 2016-2017 was supported by indicators Ground personal transport, Transport, storage and roads and Industry turnover of ground transport and transport via pipeline. Based on this analysis, we could confirm that if taxi services suffered upon market entry of UBER it should be reflected as reduced levels of these indicators. Based on tests, we have determined that average value of indicator Transport, storage and roads had increased after market entry of UBER, although this finding was not statistically significant. Similar results were measured under indicator of Industry turnover of ground transport and transport via pipeline, which showed that statistically significant change of reduced value during second observed period, the period after market entry of UBER. It is important to mention that declining tendency reflected by this indicator started in 2010, which means that the reduction of this indicator on year to year basis has not been due to influence by UBER presence.

\section{Conclusion}

Shared economy has undergone over last few years' an intensive development. In terms of platforms and its future, it is very difficult to predict how the forms of shared economy will continue to operate and what the future development will look like. In general, it is known that countries are trying to find solutions which would lead to better understanding of concepts of shared economy. It is important to register the process of development of shared forms of economy and to capture the biggest share possible. The future development of economy whether it is with some form of shared economy or without it will require all those new indicators. Due to the utilization of resources which includes labor force, it is important to measure all activities where the participation of people is present. In future, it is important to support fair competition within the market and to create effective regulatory mechanism for platforms of shared economy. Based on all the presented evidence and 
studies in this work, we can conclude that shared economy is not just a short lived trend, but on contrary it seems that this new elements of economy will continue to develop. Therefore, it is very important to focus on regulatory measures which are better designed to regulate these platforms. This better design would create an environment, where right data and statistical information provide better illustration of situations in observed countries and distinguish differences in shared economy and suppositions for future development.

\section{References}

1. E. M. Porter, R. M. Kramer, Creating Shared Value. Harvard Business Review 89, 6277 (2011)

2. W. Sutherland, M. H. Jarrahi, The Sharing Economy and Digital Platforms: A Review and Research Agenda. International Journal of Information Management 43, 328-341 (2018)

3. J. Owyang, The Collaborative Economy (2013)

4. K. Matzler, V. Veider, W. Kathan, Adapting to the Sharing Economy. Mit Sloan Management Review 56, 71-77 (2015)

5. I. Constantiou, A. Marton, V. K. Tuunainen,, Four Models of Sharing Economy Platforms. Quarterly Executive 16, 231-251 (2017)

6. W. Jing, B. Sun, Study on the Source of Negative Externality in the Sharing Economy.

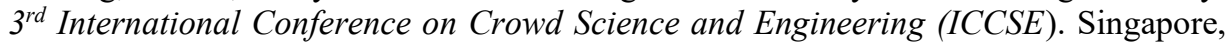
(2018)

7. S. Hall, J. Pennington, How much is the sharing economy worth to GDP? WEF, (2016)

8. Global Investor 2.15, The sharing economy New opportunities, new questions (2015)

9. T. Ch. Zhang, H. Gu, M. F. Jahromi, What makes the sharing economy successful? Computers In Human Behavior 95, 275-283 (2019)

10. T. Hodges, Public Transportation's Role in Responding to Climate Change (2010) Available at: https://www.transit.dot.gov/sites/fta.dot.gov/files/docs/Public TransportationsRoleInRespondingToClimateChange2010.pdf

11. D. Coyle, The Sharing Economy (2016) Available at: http://www.sharingeconomyuk.com/perch/resources/210116thesharingeconomyintheuk tpdc.docx1111.docx-2.pdf

12. L. Richardson, Performing thes haring economy. Geoforum 67, 121-129 (2015)

13. Ch. Bean, Independent Review of UK Economic Statistics (2016) Available at: https://assets.publishing.service.gov.uk/government/uploads/system/uploads/attachmen t_data/file/507081/2904936_Bean_Review_Web_Accessible.pdf

14. R. Basselier, G. Langenus, L. Walravens, The rise of the sharing economy (2018) Available at: https://www.nbb.be/doc/ts/publications/economicreview/2018/ecoreviii2018_h3.pdf

15. M. Cohen, A. Sundararajan, Self-Regulation and Innovation in the Peer-to-Peer Sharing Economy. University of Chicago Law Review 82 (2015)

16. Ch. Watanabe, K. Naveed, P. Neittaanmaki, B. Fox, Consolidated challenge to social demand for resilient platforms - Lessons from Uber's global expansion. Technology in Society 48, 33-53 (2017)

17. K. Thelen, Regulating Uber: The Politics of the Platform Economy in Europe and the United States. perspectives on Politics 16, 938-953 (2018) 
18. L. Pepic, The sharing economy: Uber and its efect on taxi companies. Acta Economica 16, 123-136 (2018)

19. J. Cramer, A. B. Krueger, Disruptive Change in the Taxi Business: The Case of Uber. American Economic Review 106, 177-182 (2016) 